\title{
Photocatalytic Degradation of Indigo Carmine in Aqueous Solutions by the Antibacterial Agent Pefloxacin and UVA
}

\author{
Sani S Bala ${ }^{1}$, Ahed J Alkhatib ${ }^{* 2}$, SS Bashir ${ }^{3}$ and Abdulhadi $\mathbf{M}^{4}$ \\ ${ }^{1}$ Kano University of Science and Technology, Nigeria \\ ${ }^{2}$ Department of Legal Medicine, Toxicology of Forensic Medicine, School of Medicine, Jordan University of Science and Technology, Jordan \\ ${ }^{3}$ Rabiu Musa Kkwankwaso College of Art and Remedial Science T/Wada, Nigeria \\ ${ }^{4}$ Yusuf Maitama Sule University Kano, Nigeria
}

Received: June 12, 2018; Published: June 21, 2018

*Corresponding author: Ahed J Alkhatib, Department of Legal Medicine, Toxicology of Forensic Medicine, School of Medicine, Jordan University of Science and Technology, Jordan, Tel: 00962795905145;Email: ajalkhatib@just.edu.jo

\begin{abstract}
The kinetic characteristics of the photocatalytic degradation of Indigo Carmine using anti- bacterial agent pefloxacin were experimentally investigated with respect to the initial concentration of pefloxacin, concentration and PH. The photo blanching is found to be first order in both indigo and pefloxacin. The apparent pseudo first order arte constant is proportional to the initial concentration of the pefloxacin, also the Indigo Carmine is PH dependent and is found to be more effective at PH 10. So Indigo Carmine can be successes fully decolorized using pefloxacinas as a photo sensitizer. The oxidation products of Indigo Carmine were identified as Isatin using UVA. The blue coloration of Indigo Carmine was converted into a colorless solution after irradiation. We discover that, irradiating the solution of Indigo blue and pefloxacin causes the blue color of the organic dye to fade with the rate proportional to the concentration of the pefloxacin photosensitizer. A number of approaches were used for degradation of organic dye, the photochemical kinetic method described in this text is fast, sensitive and eliminate the need for sample preparation. Hence, this photochemical method can easily be automated using flow injection analysis so as to make it faster, easier and suitable for a number of organic dye detoxification.
\end{abstract}

Keywords: Photocatalytic Degradation; Indigo Carmine; Dye; Kinetic

\section{Introduction}

\section{The Method of Chemical Kinetics}

Chemical kinetics is the study of chemical reactions with respect to reaction rate, effect of variables, formation of intermediate etc. It also includes investigation of how different experimental conditions can influence the speed of a chemical reaction. Kinetic methods are considered of great interest in chemical and pharmaceutical analysis Crouchs et al. [1]. The concept of using reaction-rate parameters to determine the initial analytical concentration of reactants dates back over a half of a century to the early literature in biochemistry, radiochemistry and phase diffusion, furthermore, among all the analysis performed in all laboratories around the world, the number carried out by kinetic-based methods probably exceeds that carried out by thermodynamics methods and direct instrumental measurement combined. This come surprise at first, until one considers the large number of enzymatic and other determinations done on multichannel autoanalysers used in clinical laboratories. Most of these rapid automated instrument use kinetic method Crouchs et al. [1].
The expanded use of automated continuous-flow sample processing in clinical and laboratories is also responsible for the increasing role that kinetics plays in contemporary analytical chemistry. In these continuous-flow procedures detection occurs in the un segmented continuous-flow stream while the system is attaining equilibrium by a physical or chemical process or both; thus, they are kinetic based Christian et al. [2]. Recent developments in instrument have contributed to a decrease in the dominance of equilibrium based methodology; consequently kinetic method is appropriate in this test. Every chemical reaction occurs at a finite rate, making it a potential candidate for a chemical kinetic method of analysis. To be effective, however, the chemical reaction must meet three necessary conditions: the reaction must not occur too quickly or too slowly; we must know the reaction's rate law; and we must be able to monitor the change in concentration for at least one species Christian et al. [2]. The increasing role of digital computer in performing computational tasks makes multipoint methods more attractive than techniques based on a small number of data points. From analytical view point, such approaches offer 
two main advantages; less experimental work is required to seek discriminating variables and the use of a large number of data point greatly reduces errors Christian et al. [2].

\section{The Reaction Rate}

The rate of the chemical reaction is the speed at which chemical reaction proceeds. It is often expressed in terms of either the concentration (amount per unit volume) of a product that is formed in a unit of time. Alternatively, it may be defined in terms of amount of the reactants consumed or product formed in a unit time. It must be fast enough that we can complete the analysis in a reasonable time, but also slow enough that the does not reach equilibrium while the reagents are mixing. As a practical limit, it is not easy to study a reaction that reaches equilibrium with several second without the aid of special equipment for rapidly mixing the reactant Christian et al. [2].

\section{The Rate Law and Rate Constant}

A rate law is an expression which relates that rate of a reaction to the rate constant and the concentrations of the reactants. A rate constant, $\mathrm{k}$, is a proportionality constant for a given reaction. The general rate law is usually expressed as:

$$
\text { Rate }=k[A] s[B] t
$$

As it can be seen from equation 1 above, the reaction rate is dependent on the concentration of the reactants as well as the rate constant. However, there are also other factors that can influence the rate of reaction. These factors include temperature and catalysts. When you are able to write a rate law equation for a certain reaction, you can determine the Reaction Order based on the values of $s$ and $t$.

\section{Isolation Method and Pseudo Condition}

If there is more than one type of reactants involved in a reaction, all the concentrations of the reactants can be kept constant except for one reactant. Measurement of the rate of the reaction as a function of its concentration can be determined. Any change in the rate is due to the reactant whose concentration was not constant. After determining the rate of this reaction, one can isolate another reactant and determine its rate. This method is called the Isolation Method because of the isolation of one reactant's concentration to calculate the overall rate of the reaction. The Isolation Method is used to determine first, second, and zero order reactions. The rate of reaction could also be determined simply by keeping all reactants concentrations constant and changing the one, which the order determined will refer to Quintero and Miranda [3]. Thus if the rate equation is:

$$
\text { Rate } \approx k[A] a[B] b
$$

By applying the isolation method, the equation will be:

$$
\text { Rate }=k(\text { pseudo })[A] a
$$

This means that the substance B is isolated by either being present in large excess or being kept constant when varying the concentration of A. This $\mathrm{k}$ (pseudo) is the pseudo rate constant and is equal to $\mathrm{k}[\mathrm{B}] \mathrm{b}$. Therefore, as the concentration of the substance $B$ is kept constant, its value is implied in the rate constant under pseudo conditions.

\section{Monitoring the Reaction}

Reaction progress kinetic analysis relies on the ability to accurately monitor the reaction conversion over time. This goal may be accomplished by following the change in concentration for at least one of its species. Which species we choose to monitor is not important; it can be one of the analytes, a reagent reacting with the analyte or the product. In order to determine the amount of substance being analyzed in solution by kinetic methods, it is necessary to measure the rate of indicator reaction. Applying the isolation method, the concentration of one of the substances (the indicator substance) changes in the course of the reaction, and the concentration of the remaining substances either do not change or its change is negligible Yatsimirskii [4].

\section{Decolorization of Indigo Carmine}

Indigo carmine (IC), which commonly known as acid blue or food blue is a dark, water soluble powder is widely used as industrial dye Marius and Secula [5]. Textile wastewaters are among the most polluted ones due to their characteristics such as high concentration oxidable substances, persistent color, low biodegradability, high pH and temperature O'neill et al. [6]. Dye-containing effluents can obstruct light penetration in the water of lakes, rivers or lagunas, thus inhibiting the biological processes based on photosynthesis. Moreover, these effluents can contain chemicals that are toxic, carcinogenic, mutagenic to various microbiological or animal species Emami et al. [7]. Indigo Carmine dye is mainly used in the textile industry for the dyeing of polyester fibers and denim Rosenstiel and Adam [8]. It is estimated that around 30\% of the applied dyes remain unfixed and are discharged in the effluent Brunton et al. [9]. Indigo Carmine is also used in food industry, cosmetics industries, as a diagnostic aid, as a redox indicator in analytical chemistry, and as a microscopic stain in biology Naora et al. [10]. Nevertheless, Indigo Carmine is a highly toxic indigoid dye and might cause skin and eye irritations to human beings. It can also cause permanent injury to cornea and conjunctiva Kleinman et al. [11], is carcinogenic and can lead to reproductive, developmental, neuro and acute toxicity. It has also been established that the dye leads to tumors at the site of application Lakowicz [12].

Indigo carmine causes irritation to the gastrointestinal tract leading to nausea, vomiting and diarrhea. It may also cause irritation to the respiratory tract such as coughing and shortness of breath Naora et al. [10]. Various technologies have been employed in order to separate Indigo Carmine from water and wastewater. So far, beside adsorption over chitin and chitosan Roberts [13] and charcoal from extracted residue of coffee beans Dayhaw-Barker and Truscott [14], electrochemical Martinez et al. [15], biological Sauvaigo et al. [16], and photochemical Iwamoto et al. [17]; Lakowicz [12]; Agrawal et al. [18] techniques have also been tested. The main advantage of the photocatalytic methods is that only the photocatalyst needs to be added and no toxic products are generated during the water decontamination. When photocatalytic decontamination 
of water is conducted using solar energy, it can provide a cheap alternative to other expensive and energy demanding chemical and electrochemical methods. Like other fluoroquinolone antibiotics, PFX is known to induce oxidative photolytic DNA cleavage Iwamoto et al. [17]. It can also induce dermatological phototoxic reactions in humans and animals upon administration of quinolone antibiotics and the exposure to and sun light Ferguson and Dawe [19]. These effects are attributed to PFX photosensitizing properties that lead to the formation of oxygen reactive species such as singlet oxygen $\left(1 \mathrm{O}_{2}\right)$, superoxide ion $\left(\mathrm{O}^{2-}\right)$, hydroxyl radical $(\mathrm{OH}$.$) and hydrogen$ peroxide $\left(\mathrm{H}_{2} \mathrm{O}_{2}\right)$ that attack the biological tissue and induce the DNA cleavage or skin inflammatory response. The ability of fluoroquinolone antibiotics to photosensitize the production of singlet oxygen, superoxide anion and hydroxyl radical has been demonstrated by spectroscopic and chemical techniques Araki and Kitaoka [20]. In this study with photochemical method demonstrate the convenience and ease of decolorizing the aqueous solution of indigo carmine dye using relatively available environmentally friendly and relatively cheap antibiotic pefloxacin as a homogeneous UVA photocatalyst for the decolorization of IC. We also highlight the ease of using the described method of using sunlight radiation as a UVA source. The method is relatively fast, cheap, does not require sample preparation and works over a stated range of $\mathrm{PH}$ In addition, the method described has a potential to develop many other experiment for the purification of noncolored organic toxins and textile industrial effluent.

\section{Study objectives}

This research is aimed at determining the photosensitivity of the aqueous solution of antibacterial pefloxacin (PFX) for decolorization organic dye (Indigo Carmine) upon irradiating the solution with UVA, and also to show the feasibility of using simple photochemical kinetic method for the determination of PFX. Furthermore, this project was done to investigate the effect of $\mathrm{PH}$ on the photo bleaching of the organic dye, indigo carmine in this photochemical method.

\section{Materials and Methods}

\section{Apparatus}

All the absorbance spectral measurement was made using Shimadzu UV-2550 uv-visible spectrophotometer in a quartz flow cell (Hellma) with path length of $10 \mathrm{~mm}$ and volume of $80 \mu \mathrm{L}$. The instrument is connected to a computer installed with spectrophotometer program. Manostat Cassette pump were used for circulating the irradiated solutions from the quartz tube in the lamp to the flow cell in the spectrophotometer. Software Sigmaplot-8 (Jandal Scientific) was used for the data analysis. $8 \mathrm{UV}$ black lamps (PHILIPS TL 8W/08F8-T5/BLB) that emit light in the region of black ultraviolet are fixed in a wood box that contain the test tube containing the sample, peristaltic pump with a flow rate of $4 \mathrm{ml}$ per minute was used to transfer the sample mixture in and out of the flow cell, so that absorbance of fresh sample can be recorded during the reaction time. Jenway $\mathrm{pH}$-meter calibrated at $\mathrm{pH} \mathrm{4,} 7$ and 9 was used for the phosphate buffer preparation.

\section{Materials}

All chemicals and solvents used were of analytical reagent grade. High purity distilled water was used throughout the measurement. The Indigo Carmine (Sigma-Aldrich). The Pefloxacin (Jordan pharmaceutical Company).All kinetic measurement was carried out at the desired $\mathrm{pH}$ value.

Reagents and Standard Solutions: Indigo carmine solution (40mg/L) was freshly prepared by dissolving $0.02000 \mathrm{~g}$ of Indigo carmine in $500 \mathrm{ml}$ distilled water. $0.25 \mathrm{M}$ Phosphate buffer of PH values: 4.0, 7.0, and10.0 and were prepared by dissolving $10.99 \mathrm{~g}$ of dipotassium hydrogen orthophosphate anhydrous $\left(\mathrm{K}_{2} \mathrm{HPO}_{4}=174.18 \mathrm{~g} / \mathrm{mol} 99 \%\right.$ assay $)$ in about $150 \mathrm{ml}$ distilled water , the buffer of pH 4.0 and 7.0 was adjusted by adding $\mathrm{HCl}$ solution stepwise until the desired $\mathrm{pH}$ is established, the buffer of $\mathrm{pH}$ 10.0 was established by adding $\mathrm{KOH}$ solution step wise until it is established, finally when the $\mathrm{pH}$ meter indicate the desired $\mathrm{pH}$ value, the solution is transferred to a $250 \mathrm{ml}$ volumetric flask and filled with distilled water to the mark.

\section{Procedure of Preparing the Reacting Solution}

Different PFX Concentration Experiments: Accurate volumes of the standard stock solution of PFX containing $5.0 \times 10^{-3}$ $\mathrm{M}$, to prepare different concentration within the range of $2.5 \times 10^{-5}$ $\mathrm{M}$ to $7.5 \times 10^{-4} \mathrm{M}$ were transferred into $50 \mathrm{~mL}$ volumetric flasks, and $10 \mathrm{~mL}$ of the phosphate buffer solution followed by $20 \mathrm{ml}$ of the IC solution were added, then the flasks were filled to the mark and mixed well, so that all these experiments was done with constant Indigo Carmine concentration of $16 \mathrm{mg} / \mathrm{L}$.

Different IC Concentrations Experiments: Accurate volumes of the standard solution of IC $(40 \mathrm{mg} / \mathrm{L}$ ) (To prepare different final concentrations within the range from 8 to $24 \mathrm{mg} / \mathrm{L}$ ) were transferred into $50 \mathrm{~mL}$ volumetric flasks, and $10 \mathrm{ml}$ of the phosphate buffer solution of the desired $\mathrm{pH}$ value followed by $5 \mathrm{ml}$ of the PFX standard stock solution of $5 \times 10^{-3} \mathrm{M}$ were added, then the flasks were filled with distilled water to the mark and mixed well, so that all these experiments was done with constant PFX concentration of $5 \times 10^{4} \mathrm{M}$.

Different pH Experiments: $10 \mathrm{~mL}$ of phosphate buffer containing $0.25 \mathrm{M}$ of constant ionic strength was used to maintain the $\mathrm{pH}$ of the reaction and different $\mathrm{pH}$ values of 4,7 and 10 was added and all these experiment were done with constant IC of $16 \mathrm{mg} / \mathrm{L}$ and $5.0 \times 10^{-4} \mathrm{M}$ PFX. Solution were prepared as follows: to a $50 \mathrm{ml}$ volumetric flask: $5 \mathrm{ml}$ of 5.0x10-3M PFX solution, $20 \mathrm{mg} / \mathrm{L}$ of $0.25 \mathrm{M}$ phosphate buffer at different $\mathrm{pH}$ values of 4,7 and 10 .

Kinetic Measurement and Solution Illumination: The illumination chamber consists of a wooden box fitted 8 Philips fluorescent black light lamps. The lamps were $8 \mathrm{~W}$ each with an emission spectrum between 300-400nm. The lamps were arranged in pairs and the distance between opposing pairs was $5 \mathrm{~cm}$. The irradiated solution was placed between the 8 lamps in quartz tube of $1 \mathrm{~cm}$ inside diameter .An electric fan was fitted at the top of the wooden box so as to maintain a constant temperature throughout the irradiation time. The absorbance of solutions was monitored 
continuously at $610 \mathrm{~nm}$ (the wave length of maximum absorbance of indigo carmine) against the corresponding reagents blank. The absorbance was measured by circulating the solution through a 1 mm capillary Teflon tube using a cassette pump at a flow rate of $4 \mathrm{~mL} / \mathrm{min}$ during the irradiation.

\section{Results and Discussion}

\section{The Reaction of Photocatalytic Degradation of Indigo Carmine (IC) in Aqueous Solution of Pefloxacin (PFX) and UVA}

The absorption spectrum of the solution containing IC, PFX as a photocatalyst and the phosphate buffer at $\mathrm{P}^{\mathrm{H}} 7$ for the reaction medium, exhibit an absorption band at $610 \mathrm{~nm}$ with no interference with any specie upon irradiation in the solution as shown in the Figure 1 . Due to the fact that only IC absorbs at $610 \mathrm{~nm}$ without any interference with any other species present in the reaction medium, the kinetics of the degradation of IC was followed by monitoring the absorbance of the solution at $610 \mathrm{~nm}$. Figure 2 shows the variation of absorbance at $610 \mathrm{~nm}$ induced upon UVA irradiation with time for the series of solutions containing equal concentration of IC $(16 \mathrm{mg} / \mathrm{L})$ and different concentration of PFX. The reaction was carried out in $\mathrm{P}^{\mathrm{H}} 7$ at room temperature.

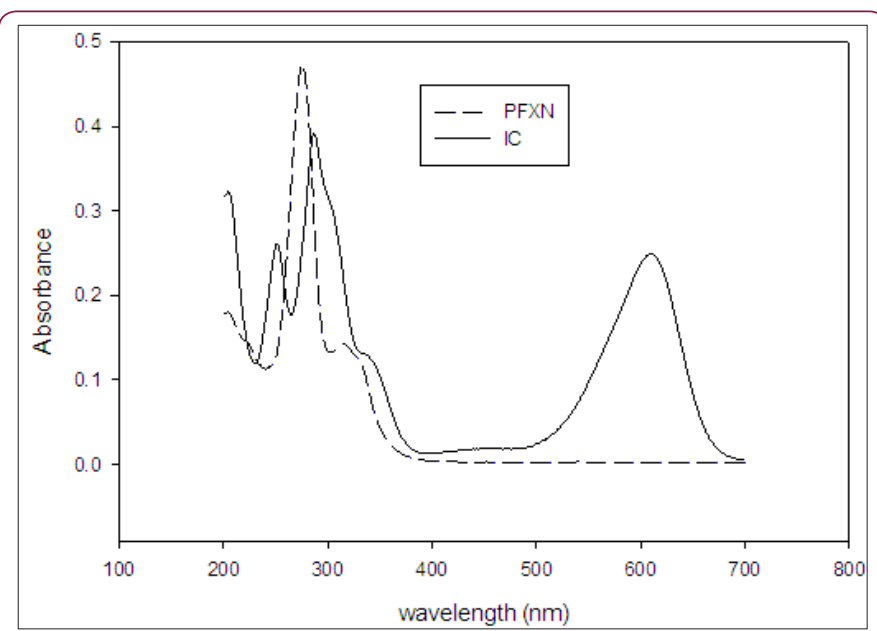

Figure 1: The absorption spectra of PFX and IC in the range of $200-700 \mathrm{~nm}$

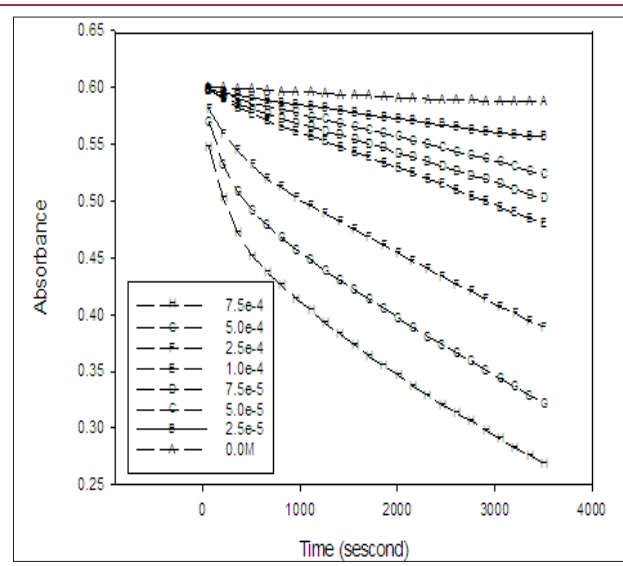

Figure 2: Variation of absorbance at $610 \mathrm{~nm}$ with irradiation time of a series of solutions containing constant concentration of IC and variable concentration of PFX at $\mathrm{pH}=7$.
Figure 2 shows that the decay of IC in absence of PFX on irradiation with UVA is very slow. The addition of PFXN to the irradiated solution significantly increases the rate of the de colourization of the IC. Furthermore, the rate of decay of the IC increases with increase in the concentration of PFXN.

It was observed that similar solution containing IC and PFX stored for extended period of time in the darkness did not show any significant change in absorbance. The observed increase in the rate of photo bleaching of IC and its dependence on the concentration of pefloxacin proves that the decay of IC is due to photosensitization of UVA by pefloxacin. Obviously the rate of de colourization of the IC is expected to show second order dependence on both and PFX. However, the PFX act as a photo sensitizer in the reaction as presumed and its concentration remain constant during the irradiation process, therefore the rate of the reaction is expected to show pseudo first order dependence of the concentration of the IC only. The nature of the absorption spectrum suggests that the rate of reaction depends on the concentration of only one of the species in the solution. Several reports show that photocatalytic oxidation of substrate exhibit pseudo first order kinetic Kettle et al. [21]. The rate law of first order reactions in terms of absorbance is given by the equation.

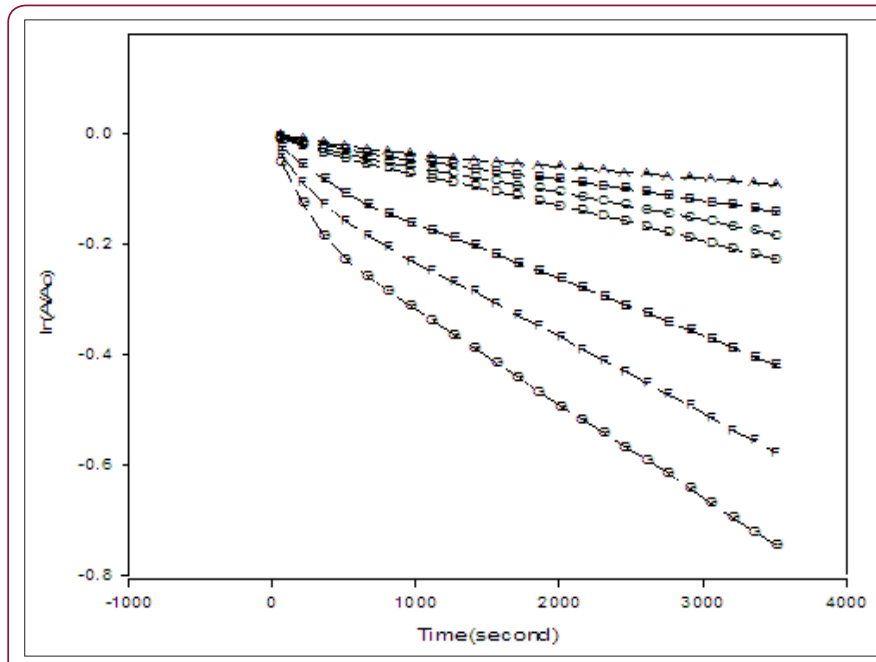

Figure 3: A plot of $\ln \left(\mathrm{A}_{\mathrm{t}} / \mathrm{A}_{\mathrm{o}}\right)$ versus time of solutions containing equal concentrations of IC $(16 \mathrm{mg} / \mathrm{L})$ and different concentration of PFX at $\mathrm{pH} 7 .(\mathrm{A})=2.5 \times 10^{-5} \mathrm{M}$, $(B)=5.0 \times 10^{-5} \mathrm{M},(\mathrm{C})=7.5 \times 10^{-5} \mathrm{M},(\mathrm{D})=1 \times 10^{-4} \mathrm{M},(\mathrm{E})=2.5 \times 10-$ $4 \mathrm{M},(\mathrm{F})=5.0 \times 10^{-4} \mathrm{M},(\mathrm{G})=7.5 \times 10^{-4} \mathrm{M}$.

Where $A_{t}$ is the absorption of solution at time $t, A_{o}$ and $A_{\infty}$ are the absorbance of the solution at the beginning and at the end of the reaction, respectively, and $\mathrm{k}_{\text {pseudo }}$ is the pseudo first order rate constant for the decay of IC. Because there was no interference from species with the absorbance of IC at $610 \mathrm{~nm}$, the value of $A_{\infty}$ in equation 3.1 was practically zero at complete de colourization. The result of plotting $\ln \left(A_{t} / A_{0}\right)$ versus time is shown in Figure 3. It was found that all the traces in Figure 4 are virtually straight lines with $\mathrm{R}^{2}$ between 0.9986 and 0.9923 showing that the photo bleaching of IC by PFX is pseudo first order in IC. The slight curvature in some the traces in Figure 4 can be attributed to existence of several mechanisms that differs in the reactive oxygen species involved in 
the bleaching of the IC. The observed pseudo first order dependence on the concentration of IC indicates that the concentration of PFX remains practically constant during irradiation. Moreover, the variation of the calculated values of $\mathrm{k}_{\text {pseudo }}$ with the concentration of CPX indicates that the photo bleaching of IC is not zero order in PFX. To determine the order of reaction in PFX, the values of $\mathrm{k}_{\text {pseudo }}$ obtained under the irradiation conditions used is plotted against the concentration of PFXN in Figure 5.

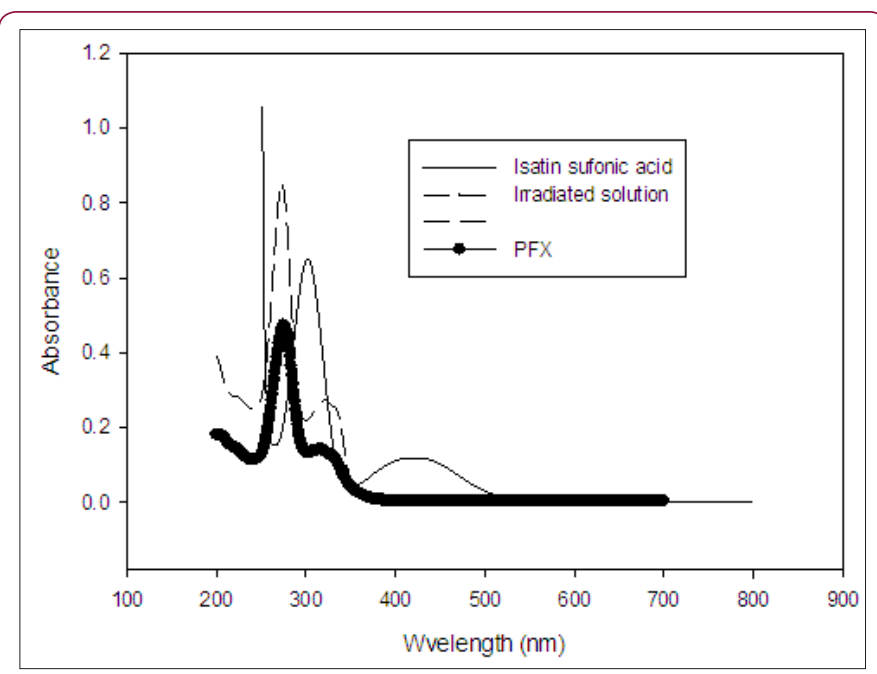

Figure 4: The absorption spectra of an irradiated solution, Pefloxacin and Isatin sulfonic acid between 200 and 700nm.

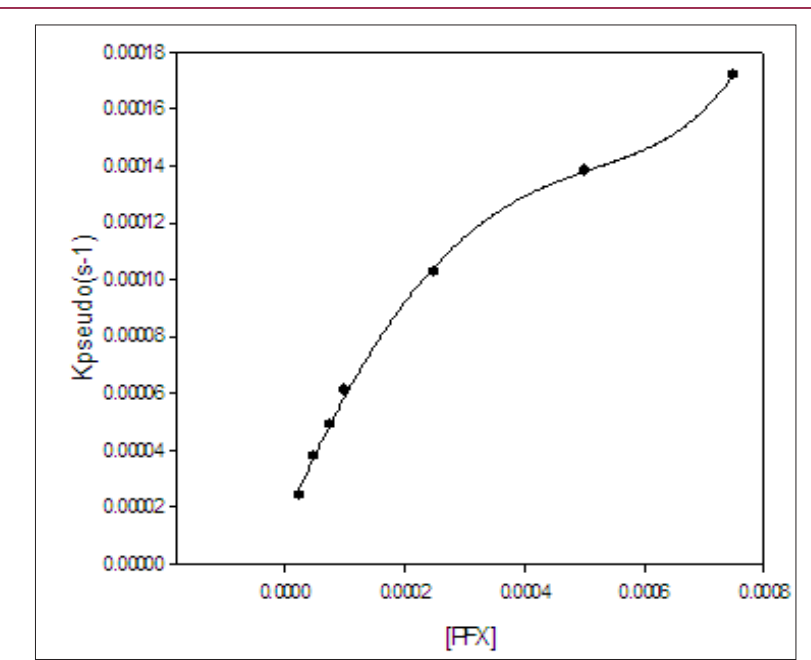

Figure 5: A plot of the calculated pseudo first order rate constant versus concentration of PFX.

The first order kinetics observed in the concentration of PFX can be attributed to the increase in the reactive oxygen species generated with increase of PFX concentration. The linear relationship between $\mathrm{k}_{\text {pseudo }}$ and the concentration of PFX indicates that the reaction's pseudo first order rate constant can be written as:

$$
k_{(\text {pseudo })}=k[P F X]
$$

Where $\mathrm{k}$ is the second order rate constant of the reaction. The overall rate of decolorization of IC can be written as:

$$
\text { Rate }=k[I C][P F X]
$$

\section{The Effect of Concentration of PFX}

The reaction between the investigated drug PFXN and Indigo Carmine in phosphate buffer at $\mathrm{P}^{\mathrm{H}} 4,7$ and 10 shows that the rate of photo degradation of IC, increased with increases in PFX concentration between $7.5 \times 10^{-4}$ and $2.5 \times 10^{-5} \mathrm{M}$. The rate of reaction was found to be drug dependent. The rates of the reaction were followed at room temperature with various concentration of the investigated drug PFX in the range of $\left(7.5 \times 10^{-4}, 5.0 \times 10^{-4}, 2.5 \times 10^{-4}\right.$, $\left.1.0 \times 10^{-4}, 7.5 \times 10^{-5}, 5.0 \times 10^{-5}, 2.5 \times 10^{-5}\right) \mathrm{M}$ at constant IC of $16 \mathrm{mg} / \mathrm{L}$ as stated above. The graph shown in Figure 3 clearly indicates that the rates obeyed the following equation:

$$
\text { Rate }=K^{\prime}[C]^{n}
$$

Where $\mathrm{K}^{\prime}$ is the pseudo-order rate constant and $\mathrm{n}$ is the order of reaction.

The rate of reactions could be estimated as $\Delta \mathrm{A} / \Delta \mathrm{t}$, where $\mathrm{A}$ is the absorbance and $t$ is the time in seconds.

\section{The Effects of the Concentration of IC}

Figure 6 shows that both IC and PFX absorb UV in the region between 300 and $400 \mathrm{~nm}$, the reactive oxygen species generated by PFX in the reaction is expected to decrease with the increase in the concentration of IC which attributed due to competition between the two specie for the absorption of photons at this range of wavelength Generally, it was observed that increasing the concentration of IC increases the de colourizatin. This result is anticipated because at high initial concentration of IC, the probability of encounters or collision with the short lived reactive oxygen species increases [2].

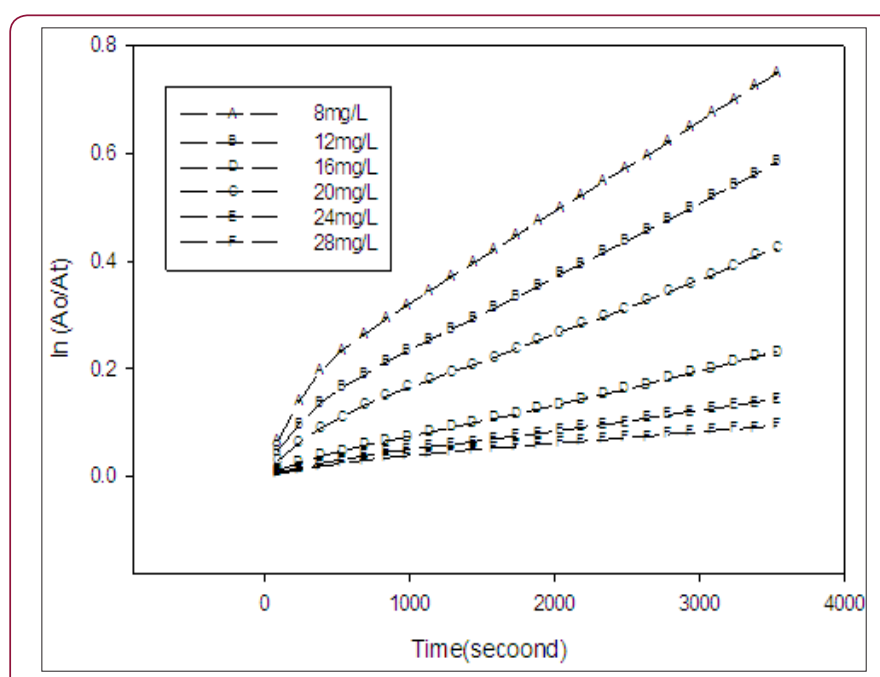

Figure 6: A plot of $\ln \left(\mathrm{A}_{0} / \mathrm{A}_{\mathrm{t}}\right)$ versus time for solutions containing different concentrations of IC and equal concentrations of $\operatorname{PFX}\left(5.0 \times 10^{-4} \mathrm{M}\right)$ at $\mathrm{pH} 7$.

\section{The PH Influence}

From the previous papers Beltran-Heredia and Sanchez-Martin [22]; Shrji [23], it was observed that $\mathrm{P}^{\mathrm{H}}$ has an important role in the photo degradation of organic substrate. Because of this fact, several experiments with different $\mathrm{P}^{\mathrm{H}}$ value was carried out at variable $\mathrm{P}^{\mathrm{H}}$ values of 4, 7 and 10 with different concentration of PFX and a fixed initial dye concentration in all cases. It was found that the photo 
bleaching rate constant at $\mathrm{P}^{\mathrm{H}} 4$ and 10 was almost the same and are both higher than at $\mathrm{P}^{\mathrm{H}} 7$. It can be suggested that the higher rate constant of the $\mathrm{P}^{\mathrm{H}} 4$ and 10 is due to more available reactive oxygen species present than at $\mathrm{P}^{\mathrm{H}} 7$ phosphate buffer. The effect of $\mathrm{PH}$ on the kinetics of IC by PFX is rather complex. In all of these $\mathrm{P}^{\mathrm{H}}$ condition the reaction is nearly monophasic and proceeds via a single mechanism. Therefore, the photo bleaching of IC in the $\mathrm{P}^{\mathrm{H}}$ ranges between 4 and 10 proceeds through a mechanism that involves the attack of IC by reactive oxygen species as an oxidant. The initial rates or pseudo first order rate constant do not provide a clear picture of a about the rate of de colourization of IC by PFX at these $\mathrm{P}^{\mathrm{H}}$ values. The better way to describe the rate of de colourization of these solution over the range of $\mathrm{P}^{\mathrm{H}} 4,7$ and 10 is the method of percent de colourization which was calculated from the absorbance of solution using the equation

$$
\% \text { decolourization }=\left(\left(A_{0}-A_{t}\right) / A_{0}\right) X 100
$$

\section{Analysis of the Irradiated Sample}

The UV- visible spectroscopy was used to analyze the composition of the Sample after irradiation at $\mathrm{P}^{\mathrm{H}}$ 7. It was found that there was a disappearance of the characteristics absorption of IC at $610 \mathrm{~nm}$ in the spectrum of the irradiated sample in Figure 3 which indicates that the IC was decolourized as compared with Figure 4. The optical spectra of irradiated solution with that of the PFX shows that both spectra contains the bands $331 \mathrm{~nm}, 322$ and $277 \mathrm{~nm}$ indicating that the PFX did not react or decay during the irradiation, also Figure 3 shows that isatin sulfonic acid exhibit two relatively strong absorption band at $244 \mathrm{~nm}$. The absorption spectra of the irradiated solution do not show those two bands. This can be attributed to further of isatin sulfonic acid to more simple products. Several report showed oxidants such as ${ }^{1} \mathrm{O}_{2}, \mathrm{O}_{2} ; \mathrm{O}_{3}, \mathrm{H}_{2} \mathrm{O}_{2}$ and, $\mathrm{OH}$ oxidize IC in several steps with first involves the formation of isatin sulfonic acid as oxidation product Araki and Kitaoka [20]. Figure 7 shows the structure of IC and isatin sulfonic acid [24].

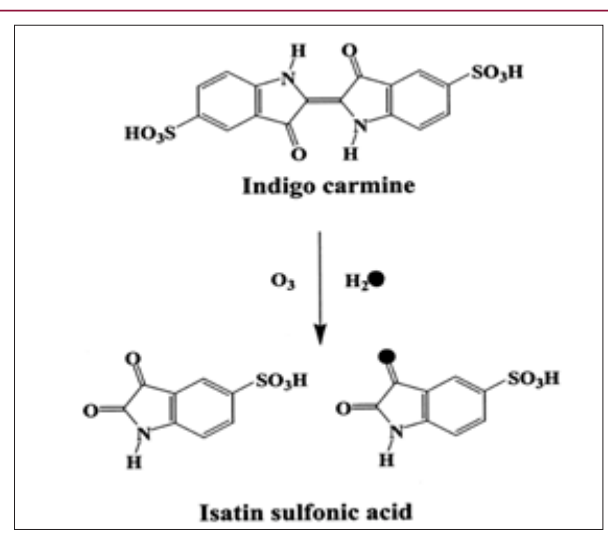

Figure 7: Ozone and superoxide converts Indigo carmine to Isatin sulfonic acid.

\section{Decolorization of IC by PFXN Using Sunlight}

The effect of sunlight as the sources of light energy for the photo bleaching if IC by PFX was tested. A solution containing $16 \mathrm{mg} / \mathrm{L}$ of IC 5.0X $10^{-4} \mathrm{M}$ PFX at $\mathrm{P}^{\mathrm{H}} 7$ was placed under the sunlight on a sunny day at noon. Reasonable percentage of IC blue colour disappeared in $1 \mathrm{hr}$, and the solution was completely decolourized within 75 minutes. Therefore the treatment of effluent from textile industries can be achieved using this rough experiment to decolourize IC by PFX and solar radiation.

\section{Conclusion}

The present study showed that a number of approaches were used for degradation of organic dye. The photochemical kinetic method described in this text is fast, sensitive and eliminate the need for sample preparation. Hence, this photochemical method can easily be automated using flow injection analysis so as to make it faster, easier and suitable for a number of organic dye detoxification.

\section{References}

1. Crouchs R Cullen, TF Scheeline (1998) Analytical chemistry 70: 53R.

2. D Christian, James E, O Reilly (1986) International analysis (2 ${ }^{\text {nd }} E d n$.); Allyn and Bacon, Inc. Boston London Sydney Toronto, UK.

3. Quintero B, Miranda MA (2000) Mechanism of photosensitization induced by drugs: A general survey. de Granada Valencia-Spain.

4. KB Yatsimirskii (1996) Kinetic methods of analysis introduction. $\left(1^{\text {st }}\right.$ Edn.); Oxford, New York: Pergamon Press, USA, pp. 155.

5. Marius S Secula (2011) An experimental study of indigo carmine removal from aqueous solution by electrocoagulation. Desalination 277(1-3): 227-235.

6. CO Neill, FR Hawkes, DL Hawkes, ND Lourenco, HM Pinheiro, et al. (1999) Colour in textile effluents-sources, measurement, discharge contents and simulation: a review. J Chem Technol Biotechnol 74: 10091018.

7. Emami S, Shafiee A, Foroumadi A (2006) Structural Features of New Quinolones and Relationship to Antibacterial Activity Against Grampositive Bacteria. Mini Reviews in Medicinal Chemistry 6(4): 375-386.

8. Von Rosenstiel N, Adam D (1994) Quinolone antibacterials. An update of their pharmacology and therapeutic use. Drugs 47(6): 872-901.

9. Brunton LL, Gilman A, Goodman, Louis Sanford (2011) Goodman \& Gilman's the pharmacological basis of therapeutics: McGraw-Hill Medical, New York, USA.

10. Naora K, Katagiri Y, Ichikawa N, Hayashibara M, Iwamoto K (1990) A Possible Reduction in the Renal Clearance of Ciprofloxacin by Fenbufen in Rats. J Pharm Pharmacol 42(10): 704-707.

11. Kleinman MH, Smith MD, Kurali E, Kleinpeter S, Jiang K, et al. (2010) An evaluation of chemical photoreactivity and the relationship to phototoxicity. Regul Toxicol Pharmacol 58(2): 224-232.

12. Lakowicz JR (2001) Radiative decay engineering: biophysical and biomedical applications. Anal Biochem 298(1): 1-24.

13. Roberts JE (2002) Screening for Ocular Phototoxicity. Int J Toxicol 21(6): 491-500.

14. Dayhaw-Barker P, Truscott TG (1988) Direct Detection of Singlet Oxygen Sensitized By Nalidixic Acid: The Effect Of pH And Melanin. Photochem Photobiol 47(5): 765-767.

15. Martinez LJ, Sik RH, Chignell CF (1998) Fluoroquinolone Antimicrobials: Singlet Oxygen, Superoxide and Phototoxicity. PhotochemPhotobiol 67(4): 399-403

16. Sauvaigo S, Douki T, Odin F, Caillat S, Ravanat JL, et al. (2001) Analysis of Fluoroquinolone-mediated Photosensitization of 2'-Deoxyguanosine, Calf Thymus and Cellular DNA: Determination of Type-I, Type-II and 
Triplet-Triplet Energy Transfer Mechanism Contribution. Photochem Photobiol 73(3): 230-237.

17. Iwamoto Y, Kurita A, Shimizu T, Masuzawa T, Uno K, et al. (1994) DNA strand-breaking activities of quinolone antimicrobial agents under visible light irradiation. Biol Pharm Bull 17(5): 654-657.

18. Agrawal N, Ray RS, Farooq M, Pant AB, Hans RK (2007) Photosensitizing potential of ciprofloxacin at ambient level of UV radiation. Photochem Photobiol 83(5): 1226-1236.

19. Ferguson J, Dawe R (1997) Phototoxicity in quinolones: comparison of ciprofloxacin and grepafloxacin. J Antimicrob Chemother 40: 93-98.

20. Araki T, Kitaoka H (1998) ESR Detection of free radical and active oxygen species generated during photolysis of fluoroquinolones. Chem Pharm Bull (Tokyo) 46(6): 1021-1026.

(C) This work is licensed under Creative

Submission Link: https://biomedres.us/submit-manuscript.php
21. Kettle AJ, Clark BM, Winterbourn CC (2004) Superoxide Converts Indigo Carmine to Isatin Sulfonic Acid Implications for The Hypothesis That Neutrophils Produce Ozone. J Biol Chem 279(18): 18521-18525.

22.J Beltran-Heredia, J Sanchez-Martin (2009) Removal of Carmine Indigo Dye with Moringaoleifera Seed Extract. Ind Eng Chem Res 48: 65126520.

23. Hisashi Shrji (2014) Molecular analysis of quinolone resistance Haemophilus influenza: validation of the mutations in Quinolone Resistance-Determining Regions. Journal of infection and chemotherapy 20(4): 250-255.

24. Sultan SM (1988) Kinetic determination of propranolol in drug formulations. Analyst 1113(1): 149-152.

$\begin{array}{ll}\text { BIOMEDICAL } & \text { Assets of Publishing with us } \\ \text { RESEARCHES } & \text { - Global archiving of articles } \\ & \text { - Immediate, unrestricted online access } \\ & \text { - Rigorous Peer Review Process } \\ & \text { - Authors Retain Copyrights } \\ \end{array}$

